\title{
Contribution of some agronomic traits to durum wheat performance in a dry Mediterranean region of Northern Syria
}

\author{
P Annicchiarico *, L Pecetti * \\ International Center for Agricultural Research in the Dry Areas (ICARDA), Aleppo, Syria
}

(Received 15 March 1992; accepted 12 October 1992)

\begin{abstract}
Summary - The study assessed the possible role of some agronomic traits in an integrated breeding approach to select durum wheats for a dry Mediterranean region in Northern Syria. Sixty-three entries of various origins, previously tested for adaptation to the target region, were grown at 2 locations during 2 seasons sharply contrasting for rainfall amount and distribution, and definable on the whole as "favorable" and "unfavorable" for the crop in the area. While heading and maturity time and kernel number/spike always correlated with grain yield, other traits correlated either in the wetter or in the drier season. The capability of each trait to identify materials with high and stable yield across the contrasting seasons was assessed by discriminant analysis. Early heading and high kernel number/spike were consistent features of these materials. However, the contribution of these traits to genotype discrimination proved rather limited when combined with grain yield information. Multivariate comparison among the best genotypes showed that similar yield responses could be attained by genotypes with very differing architectures of favorable traits.
\end{abstract}

agronomic character / durum wheat / Mediterranean region / plant ideotype / selection / Triticum turgidum var durum

Résumé - Contribution de quelques caractères agronomiques au rendement du blé dur dans une région méditerranéenne sèche du Nord de la Syrie. L'étude a examiné le rôle potentiel que quelques caractères agronomiques peuvent jouer dans la sélection de blés durs pour une région méditerranéenne du Nord de la Syrie. Soixantetrois génotypes d'origines différentes, dont l'adaptation à la région donnée avait déjà été vérifiée, ont été comparés en 2 localités pendant 2 saisons très contrastées quant à leur niveau et distribution de précipitation et pouvant être définies dans l'ensemble comme "favorable" et "défavorable" pour la culture dans la région. Précocité d'épiaison et nombre de grains par épi ont toujours été corrélés avec le rendement, tandis que d'autres caractères ont été corrélés au rendement soit dans le cas de l'année humide, soit dans le cas de l'année sèche. La capacité des caractères à identifier les génotypes à rendement haut et stable au cours des 2 années a été établie par analyse discriminante. Ces génotypes ont toujours été caractérisés par un certain niveau de précocité et par un nombre élevé de grains par épi. Cependant, la contribution de ces caractères à la discrimination des génotypes s'est révélée plutôt limitée lorsque leur information a été combinée à celle donnée par le rendement. La comparaison multivariée parmi les meilleurs génotypes a montré que des performances similaires peuvent être atteintes par des génotypes avec des combinaisons très variées de caractères favorables.

caractère agronomique / blé dur / région méditerranéenne / idéotype de plante / sélection /Triticum turgidum var durum

\footnotetext{
* Present address: Istituto Sperimentale per le Colture Foraggere, Viale Piacenza 29, 20075 Lodi (MI), Italy
} 


\section{INTRODUCTION}

More than $50 \%$ of durum wheat (Triticum turgidum var durum) in West Asia and North Africa is grown in semi-arid areas with $<400 \mathrm{~mm}$ long-term average annual rainfall (ICARDA, 1989). Climatic conditions and especially annual precipitation are subjected to wide year-to-year fluctuations in these environments. A high level of yield stability is a necessary feature of the improved germplasm for these areas, which must be tolerant to drought to prevent crop failures in the un-favorable seasons, and possess a satisfactory yield potential to respond to the favorable seasons (Nachit and $\mathrm{Ke}$ tata, 1987; Ceccarelli et al, 1991).

Due to the occurrence of large genotype $x$ environment interactions, grain yield per se has a rather low broad sense heritability especially in the less favorable environments (Blum, 1988; Ceccarelli et al, 1991). The potential value of a number of agronomic traits to be used along with grain yield in an integrated breeding approach has been repeatedly discussed in the past (Richards, 1982; Clarke, 1987; Marshall, 1987) as a tool to make genotype selection for these areas more cost-effective.

The present study aimed at assessing the possible contribution of a set of agronomic characters to genotype selection for a dry Mediterranean region in Northern Syria. A number of adapted durum wheat entries of diverse geographic origin were grown in 2 contrasting seasons representative of the wide range of precipitation fluctuation typical of the region. The study included: i) the observation of the relationship between grain yield and the agronomic traits at varying environmental mean yields; ii) the assessment, separately in each season, of the contribution of these traits to the identification of the stable and high yielding materials across the 2 seasons; and iii) the possible identification of one or more definite character architectures for traits related to grain yield in those materials characterized by a desirable level of yield and yield stability.

\section{MATERIALS AND METHODS}

\section{Experiment management}

The trials were carried out during the cropping seasons 1987-1988 and 1988-1989 at 2 locations in northern Syria, namely Tel Hadya $\left(36^{\circ} 01^{\prime} \mathrm{N}, 36^{\circ} 56^{\prime} \mathrm{E}, 284 \mathrm{~m}\right.$ elevation), a semi-arid site characterized by a long-term average annual rainfall of $348 \mathrm{~mm}$ and relatively good soil fertility, and Breda $\left(35^{\circ} 56^{\prime} \mathrm{N}, 37^{\circ} 11^{\prime} \mathrm{E}, 300 \mathrm{~m}\right.$ elevation), with a long-term average annual rainfall of 269 $\mathrm{mm}$ and a rather low soil fertility. Rainfall in Tel Hadya and Breda was respectively $504 \mathrm{~mm}$ and $415 \mathrm{~mm}$ in $1987-1988$ and $234 \mathrm{~mm}$ and $194 \mathrm{~mm}$ in 1988-1989, the rainfall at both locations being about $50 \%$ above and $30 \%$ below the long-term average in the 2 seasons. The rainfall distributions by 10-d intervals are reported in figure 1. It is evident that in 1987-1988 the rainfall was evenly distributed along the crop cycle, while in 1988-1989 a severe period of drought occurred from the tillering stage onwards. In the latter season, the shower which occurred at the beginning of May during the grain filling period likely avoided complete crop failure. On the basis of both rainfall amount and distribution, 1987-1988 and 1988-1989 can be regarded as a favorable and an unfavorable season, respectively.

Mainly because of their differences in soil fertility, the 2 locations can also be regarded as favorable (Tel Hadya) and unfavorable (Breda) within the same target region, so that the factor "site" could also be considered in this study together with the factor "season".

The experiments included 63 entries, 60 of which had been classified as drought tolerant in an evaluation of a world durum wheat germplasm collection previously carried out in the region (Pecetti and Annicchiarico, 1991). These entries belonged to 17 country gene pools, viz Morocco (16 entries), Tunisia (14), Turkey (5), Italy (5), Greece (4), Jordan (3) and eleven other countries with 1 or 2 entries each. One entry was of unknown origin. Apart from 6 breeding lines and 2 of unknown status, all other entries were either landraces or old cultivars. In addition, we also included in the experiments 3 control cultivars which seemed to represent 3 stages of the crop improvement in the area. These were "Haurani", a landrace widely grown in the less favorable cropping zones of the region, "Sham 1", an improved variety selected by the CIMMYT-ICARDA joint durum wheat project and characterized by high and stable yields under moderate drought stress, and "Om Rabi 9", a genotype belonging to a family of ICARDA breeding lines which seem promising for their good adaptation to the entire range of environments in the region (Nachit and Ketata, 1986).

The experimental design consisted of a randomized complete block with 2 replications. The harvested plot size was $3 \mathrm{~m}^{2}$ ( 4 rows, $2.5 \mathrm{~m}$ long, $30 \mathrm{~cm}$ apart). Sowing was always carried out in the last week of November at a rate of ca 250 seeds $/ \mathrm{m}^{2}$. The fertilization rate was $40 \mathrm{~kg} / \mathrm{ha} \mathrm{N}$ plus $40 \mathrm{~kg} / \mathrm{ha} \mathrm{P}_{2} \mathrm{O}_{5}$.

Ten agronomic characters were considered besides grain yield $(Y L D)$ in this study, namely: early growth vigour ( $E G V$, days to heading $(D H E)$, days to maturity $(D M A)$, grain-filling period (GFP), plant height $(P L H)$, peduncle length $(P E L)$, leaf senescence ( $L E S)$, number of spikes per unit area $(S P I)$, number of kernels per spike (SSP) and 1000 -kernel weight (TKW). EGV was scored at tillering stage using a 5-level scale ( $1=$ very poor to $5=$ very good). $D H E$ and $D M A$ were counted from the first sufficient rainfall for germination to when $50 \%$ anthesis and $50 \%$ physiological maturity 
1997-89

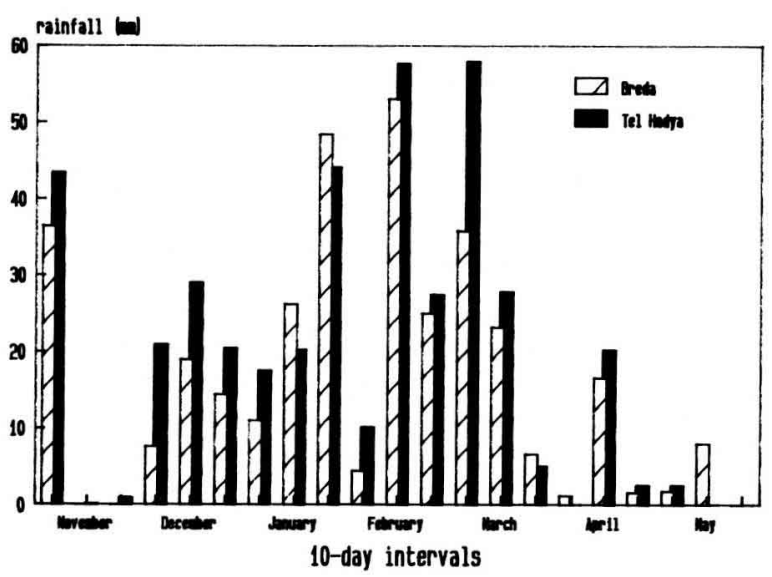

$1988-89$

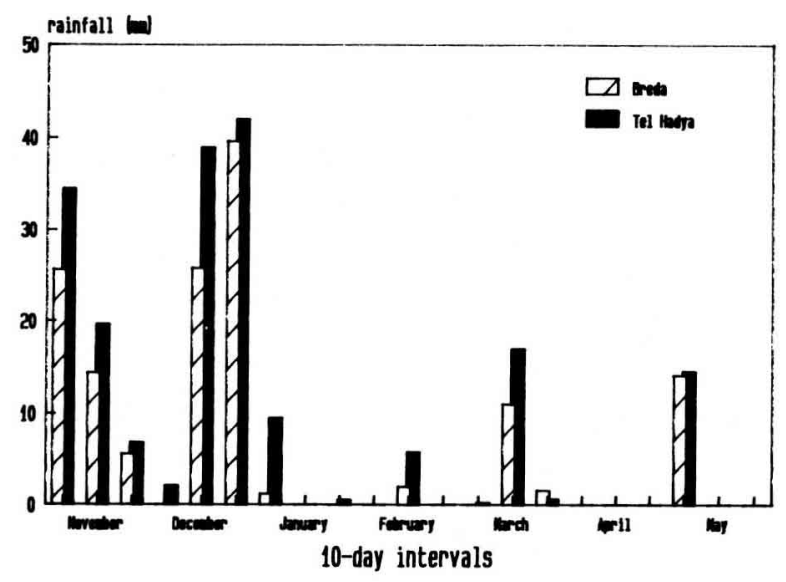

Fig 1. Rainfall distribution by 10-d intervals in the 2 seasons and sites of evaluation.

(yellowed uppermost internode), respectively, occurred. GFP was calculated as the difference between days to maturity and days to heading. $P L H$ and $P E L$ were recorded at maturity on 3 representative plants in each plot. The latter character was measured as the distance between the last node and the base of the spike. LES was scored $14 \mathrm{~d}$ after heading date using a 5 -level scale $(1=$ very limited leaf senescence to $5=$ extended plant senescence). SPI was counted in each plot using a $0.6 \mathrm{~m} \times 0.6 \mathrm{~m}$ quadrat. $S S P$ and $T K W$ were measured on a sample of 3 spikes randomly harvested from each plot. $P E L$ and $L E S$ were not recorded at Tel Hadya during 1987-1988.

\section{Statistical analyses}

\section{Relationship between grain yield and agronomic characters at varying environmental mean yields}

Simple correlation coefficients between grain yield and the other characters were calculated for each site in each season. In order to better display the seasonal effects, the same correlations were also computed for each season on the averaged values over sites and compared as described by Dagnelie (1975a).

\section{Contribution of agronomic characters to the identification of stable and high yielding materials}

The entries were subdivided into 2 groups of "selected" and "non-selected" on the basis of their yield and stability of yield on the 4 environments. Genotype mean yields in each environment were first expressed as percentage values of the environment mean. Entries were assigned to the "selected" group if their average percentage value over sites and seasons was $>110$, being not less than 95 in any case and $>100$ in at least 3 cases out of 4 . The entry stability taken into account by the given selection criterion seemed important to define the value of a genotype in the region. The materials which performed consistently well across the 2 contrasting seasons and sites are likely to perform as well under growing conditions which are moderately favorable or unfavorable within the given extremes of rainfall amount and distribution and soil fertility.

For each character, a partially hierarchical analysis of variance (ANOVA) was executed according to the following model combining the factors $G=$ group, $D=$ entry within group, $S=$ site, $Y=$ season and $B=$ block to describe the yield $Y_{i j k / r}$ of the th entry included in the th group and grown in the kth site, the th season and the ith block:

$$
\begin{aligned}
Y_{i j k l r} & =\mu+G_{j}+D_{j i}+S_{k}+y_{1}+B_{k l r}+G S_{j k}+G Y_{j l}+D S_{j j k} \\
& +D Y_{j l l}+S Y_{k l}+G S Y_{j k l}+D S Y_{j k k l}+G B_{j k l r}+\varepsilon_{j i k l r}
\end{aligned}
$$

"Entry within group" was considered as a random factor as a well as "block", while "site", "season" and "group" were considered as fixed factors in the analysis.

A second ANOVA was conducted separately for each season to better display the season effect onto the 2 groups for those characters which were significant at the "group" level in the previous ANOVA.

A discriminant analysis was used to assess in each season combinations of traits able to discriminate between the 2 groups. In the case of discrimination between only two populations, the discriminant analysis is analogous to a multiple regression analysis where the dependent variable is a dummy variable indicating the 2 populations (Dagnelie, 1975b). $D M A$ was excluded from the analysis to avoid multicollinearity due to simultaneous presence of $D H E$, $D M A$ and GFP. The analysis was run both with and without YLD information, since both situations were thought to be of practical interest for breeding. The different models were compared on the basis of their adjusted $R^{2}$ and their probability of misclassification corrected according to the method proposed by Lachenbruch (1968). 


\section{Possible identification of different character architectures within the best materials}

\begin{abstract}
"Selected" entries were subjected to a principal component analysis (PCA) with the aim of identifying possible plant "ideotypes" resulting in a similar yield performance and stability. For comparison, the average value of the "non-selected" materials was included in the PCA together with the "selected" ones. The original variables entering the PCA included: i) the variables for which group means had differed in each season (reported later in table II) with the exception of $Y L D$ and $D M A$, the latter being highly correlated with DHE ( $r=0.89$ in 1987-1988 and $r=0.84$ in 1988-1989, $P \leq 0.001$ ); ii) other variables which did not satisfy the above-mentioned condition but were correlated with grain yield in the selected group, a $P$ level $\leq 0.10$ being retained as significant due to the limited number of entries. A last condition for a chosen variable to enter the PCA was that the differences among the "selected" entries for that variable had to be significant according to ANOVA. Results of the PCA were summarized by a hierarchical cluster analysis executed on the principal components which had resulted significant $(P \leq 0.001)$ according to the $\chi^{2}$ test described by Dagnelie (1975b). For the cluster analysis, we adopted the average linkage method (Sokal and Michener, 1958) and a truncation level for grouping of $50 \%$ similarity. Some groups of related entries were identified and further compared by ANOVA and Duncan's multiple range test (Duncan, 1955). The SAS computer software was adopted for all computations.
\end{abstract}

\section{RESULTS}

\section{Relationship between grain yield and agronomic characters at varying environmental mean yields}

Table I reports mean yield and rainfall for each site and season of evaluation. Grain yield variability could be attributed mostly to rainfall, 0.95 being the coefficient of determination for this factor. The correlation between entry mean yields in the 2 seasons was 0.43 , while that between entry mean yields in the 2 locations was 0.57 . This result suggested that the factor "season" could have determined a larger interaction with the genotypes than the factor "site". Correlation coefficients between grain yield and other agronomic characters are also reported in table I. TKW never showed any significant correlation with grain yield as neither did EGV except in one case. Conversely, DHE, DMA and SSP always had significant correlations with grain yield. The cor- relation coefficients of the remaining traits showed a more or less marked trend in function of the environmental mean value. In particular, GFP and PLH were significantly correlated to yield only in the 2 environments with the highest mean yields, whereas PEL, LES and SPI correlated only in the 2 environments with the lowest mean yields. Seasonal effects on correlation coefficients were shown after averaging trait values over sites in each season. The coefficients in the 2 seasons significantly differed as for GFP, PLH and PEL.

\section{Contribution of agronomic characters to the identification of stable and high yielding materials}

As a result of the previously described selection process, 16 entries were included in the "selected" group, while the remaining 47 constituted the "non-selected" group. Apart from "Sham 1", "Om Rabi 9" and one entry of unknown status, the former group comprised only landraces and old cultivars. Results of the combined ANOVA including the factor "group" can be summarized as follows. Significant differences between groups were present for all characters except $E G V, P E L, T K W$ and SPI. For the latter character, a certain trend towards a higher value in the "selected" group was evident but it did not reach statistical significance. On average, "selected" materials, apart from being better yielding, were earlier in heading and maturity, had a longer grain-filling period, were shorter in stature, had a slower leaf senescence, and had a higher number of kernels per spike. The diversity of the materials included in the experiments was confirmed by the highly significant $(P \leq 0.001)$ differences among entries within groups for all characters. In general, the factor "season" had a more pronounced influence than the factor "site" on the trait values. As a matter of fact, the two seasons greatly differed for all characters, the dry season being characterized by lower values for all traits except $L E S$. Conversely, the 2 sites differed only as for DHE and DMA ( $P \leq$ $0.001), P L H(P \leq 0.01), P E L$ and $S S P(P \leq$ $0.05)$, as well as $Y L D(P \leq 0.001)$, the lower values for those traits being recorded in the less favorable site. "Group x season" interaction was significant for $P L H(P \leq 0.001), Y L D$ and $D H E$ $(P \leq 0.01)$, and GFP $(P \leq 0.05)$, while "group $\mathrm{x}$ site" interaction was significant $(P \leq 0.05)$ only for $Y L D$, thus justifying averaging over sites the 
Table I. Correlation coefficients ( $r$ ) between grain yield and other agronomic traits recorded on durum wheat. A) coefficients in each evaluation environment. B) coefficients in each season, after averaging data over sites, and $u$-value for comparison of the $r$ values.

\begin{tabular}{|c|c|c|c|c|c|c|c|c|}
\hline \multirow[t]{2}{*}{ Saison } & & \multicolumn{2}{|c|}{$1987-1988$} & \multicolumn{2}{|c|}{$1988-1989$} & \multirow[t]{2}{*}{$1987-1988$} & \multirow[t]{2}{*}{$1988-1989$} & \multirow[t]{2}{*}{ u-value } \\
\hline & & Breda & Tel Hadya & Breda & Tel Hadya & & & \\
\hline \multicolumn{9}{|l|}{ Site } \\
\hline Mean yield (t/ha) & & 2.067 & 3.399 & 0.743 & 0.702 & & & \\
\hline Rainfall (mm) & & 415 & 504 & 194 & 234 & & & \\
\hline \multicolumn{9}{|l|}{ Trait } \\
\hline Early growth vigour & $(E G V)$ & 0.42 & 0.05 & 0.14 & 0.20 & 0.28 & 0.18 & 0.61 \\
\hline Days to heading & $(D H E)$ & -0.51 & -0.63 & -0.63 & -0.67 & -0.71 & -0.73 & 0.33 \\
\hline Days to maturity & (DMA) & -0.51 & -0.34 & -0.47 & -0.37 & -0.56 & -0.53 & 0.22 \\
\hline Grain-filling period & $(G F P)$ & 0.32 & 0.74 & 0.23 & 0.25 & 0.68 & 0.18 & $3.59^{\star \star \star}$ \\
\hline Plant height & $(P L H)$ & -0.37 & -0.72 & 0.24 & 0.15 & -0.70 & 0.01 & $4.86^{\star \star \star}$ \\
\hline Peduncle length & $(P E L)$ & -0.04 & - & 0.37 & 0.25 & -0.24 & 0.30 & $2.54^{\star}$ \\
\hline Leaf senescence & (LES) & -0.20 & - & -0.26 & -0.34 & -0.31 & -0.41 & 0.66 \\
\hline No. spikes/unit area & $(S P I)$ & 0.21 & 0.17 & 0.30 & 0.38 & 0.22 & 0.39 & 1.05 \\
\hline No. kernels/spike & $(S S P)$ & 0.28 & 0.51 & 0.41 & 0.52 & 0.51 & 0.62 & 0.94 \\
\hline 1000-kernel weight & $(T K W)$ & -0.16 & 0.02 & -0.08 & -0.23 & -0.09 & -0.28 & 0.83 \\
\hline
\end{tabular}

Threshold values for $r$ significant at $P \leq 0.05, P \leq 0.01$ and $P \leq 0.001$ are $0.248,0.324$ and 0.406 , respectively. ${ }^{*}$ and ${ }^{* * *}$ significant at $P \leq 0.05$ and $P \leq 0.001$, respectively.

seasonal values in all further analyses. Even though both the effects "entry (group) $x$ season" and "entry (group) $x$ site" were highly significant $(P \leq 0.001)$ for yield, the estimated variance of the former effect relative to the latter was 1.46fold greater. The nature of the "group $x$ season" interactions is evidenced in table 11 reporting group mean and range, and comparison of means separately in each season. The differences between groups for the above-mentioned characters were greater in the favorable season than in the unfavorable one, being the difference for GFP and PLH even not significant in 1988-1989. In fact, also LES was significant only in one season. "Selected" materials were earlier both in heading and maturity and had a higher number of kernels per spike consistently across seasons.

When the distinctiveness between the 2 groups was assessed in a multivariate sense, the models with up to 3 variables that are reported in table III, either including grain yield or not, were identified as the most discriminating in each season. Taking into account the parameters considered and the fact that a model with a reduced number of variables is more appealing, the mod- els including YLD with GFP in 1987-1988 and with SSP in 1988-1989 could be ranked as the best. However, the inclusion of other characters beside grain yield in the discriminating models resulted in a limited contribution to reducing the probability of misclassification. It is noteworthy that the combination of $D H E$ and SSP was able to discriminate between the groups as much as grain yield per se in the dry season and only slightly less in the wet season. Their successful combination could be attributed to the fact that these traits, though both related to yield, were little correlated among themselves in both seasons $(r=-0.22$ in 1987-1988, $r=-0.34$ in 1988-1989).

\section{Possible identification of different character architectures within the best materials}

As a result of the previously described variable selection criterion, DHE, GFP, PLH and SSP recorded in 1987-1988, and DHE, GFP, PLH, TKW, LES and SSP recorded in 1988-1989 entered the principal component analysis $(P C A)$ as original variables. The "selected" group sub- 
Table II. Seasonal group mean comparison and range values of the 2 groups of durum wheat entries for the characters significant at the "group" level in the combined ANOVA.

\begin{tabular}{|c|c|c|c|c|c|}
\hline \multirow[t]{2}{*}{ Character } & \multirow[t]{2}{*}{ Season } & \multicolumn{2}{|c|}{ Selected } & \multicolumn{2}{|c|}{ Non-selected } \\
\hline & & Mean & Range & Mean & Range \\
\hline$Y L D$ (t/ha) & $\begin{array}{l}1987-1988 \\
1988-1989\end{array}$ & $\begin{array}{l}3.214^{* \star \star *} \\
0.888^{\star \star *}\end{array}$ & $\begin{array}{l}2.760-4.063 \\
0.789-1.053\end{array}$ & $\begin{array}{l}2.569 \\
0.667\end{array}$ & $\begin{array}{l}1.925-3.576 \\
0.294-0.939\end{array}$ \\
\hline$D H E$ (dd) & $\begin{array}{l}1987-1988 \\
1988-1989\end{array}$ & $\begin{array}{l}134.9^{* \star *} \\
129.1^{* \star *}\end{array}$ & $\begin{array}{l}129.7-141.4 \\
125.0-133.7\end{array}$ & $\begin{array}{l}141.0 \\
133.5\end{array}$ & $\begin{array}{l}131.9-151.2 \\
126.8-141.5\end{array}$ \\
\hline$D M A(d d)$ & $\begin{array}{l}1987-1988 \\
1988-1989\end{array}$ & $\begin{array}{l}167.3^{\star *} \\
156.7^{\star}\end{array}$ & $\begin{array}{l}165.8-170.1 \\
153.0-162.4\end{array}$ & $\begin{array}{l}170.1 \\
159.7\end{array}$ & $\begin{array}{l}164.6-176.7 \\
152.7-166.8\end{array}$ \\
\hline$G F P(\mathrm{dd})$ & $\begin{array}{l}1987-1988 \\
1988-1989\end{array}$ & $\begin{array}{l}32.4^{* * *} \\
27.6\end{array}$ & $\begin{array}{l}28.1-36.3 \\
24.3-31.4\end{array}$ & $\begin{array}{l}29.1 \\
26.2\end{array}$ & $\begin{array}{l}25.4-34.9 \\
20.2-31.8\end{array}$ \\
\hline$P L H(\mathrm{~cm})$ & $\begin{array}{l}1987-1988 \\
1988-1989\end{array}$ & $\begin{array}{l}112.0^{\star \star \star \star} \\
54.9\end{array}$ & $\begin{array}{l}90.0-138.3 \\
46.1-67.4\end{array}$ & $\begin{array}{l}128.3 \\
56.2\end{array}$ & $\begin{array}{l}79.3-158.8 \\
43.8-70.9\end{array}$ \\
\hline LES (score) & $\begin{array}{l}1987-1988 \\
1988-1989\end{array}$ & $\begin{array}{l}2.3 \\
2.7^{* \star}\end{array}$ & $\begin{array}{l}1.0-5.0 \\
2.0-3.2\end{array}$ & $\begin{array}{l}2.8 \\
2.9\end{array}$ & $\begin{array}{l}1.2-4.6 \\
2.5-3.3\end{array}$ \\
\hline$S S P($ no) & $\begin{array}{c}1987-1988 \\
1988-1989\end{array}$ & $\begin{array}{l}46.7^{\star \star \star} \\
26.5^{\star \star \star \star}\end{array}$ & $\begin{array}{l}37.3-57.8 \\
20.9-34.6\end{array}$ & $\begin{array}{l}41.7 \\
21.5\end{array}$ & $\begin{array}{l}31.8-58.2 \\
11.2-28.3\end{array}$ \\
\hline
\end{tabular}

$\because " *$ and ${ }^{* * *}$ group means differing at $P \leq 0.05, P \leq 0.01$ and $P \leq 0.001$, respectively.

jected to $P C A$ included 5 entries from Morocco (coded as $A, B, F, G$ and $M$ ), 3 entries from Tunisia (C, $E$ and $I), 3$ entries from Greece (D, $J$ and $N$ ), one from Italy $(K)$, one from Jordan $(P)$, one of unknown origin (L), and the 2 control cultivars "Sham 1" (S) and "Om Rabi 9" (O). The average value of the "non-selected" group was coded as $\mathrm{X}$. The first 2 principal components (PRIN) summarized $64.4 \%$ of the total variance. Entry variability in function of these axes is reported in figure 2. PRIN-1 appeared as a general, negative indicator of yield. This was shown by the co-ordinate value of the "non-selected" group as well as by the trait eigenvectors of this component, which was mainly related to $D H E$ 87-88 and 88-89 (0.44 and 0.32), PLH 87-88 (0.42), GFP 87-88 $(-0.41)$ and SSP $87-88$ and 88-89 (-0.32 and -0.19$)$. PRIN-2 showed the highest eigenvectors for GFP 88-89 $(-0.54)$, DHE 88-89 (0.41), SSP 87-88 and 88-89 (0.38 and 0.39 ) and $T K W$ 88-89 (-0.38). It mainly separated the 2 improved cultivars, characterized by a high number of kernels per spike in both seasons and a certain lateness in 19881989 , from the other entries which had a relatively longer GFP and higher TKW in 19881989.

Cluster analysis performed for the "selected" entries on the first 5 principal components identified 5 clusters. The 1st cluster grouped the $2 \mathrm{im}$ proved cultivars (entries $O$ and $S$ ). The 2nd included all the entries from Morocco (A, B, F, G and $M$ ). The 3rd included entries $D, J, K$ and $N$ : the similarity of $D, J$ and $K$ can be explained by the nature of these accessions, being $K$ the old Italian cultivar "Capeiti", D the same cultivar introduced into cultivation and re-collected in Greece, and $\mathrm{J}$ the Greek cultivar "Atsiki 5" that possibly derived from "Capeiti" according to Damania and Somaroo (1988). The 4th cluster included only the Tunisian accession "17870" (C), while the 5th grouped the 2 remaining entries from Tunisia together with the one from Jordan and the one of unknown origin ( $E, I, P$ and $L$ ).

The clusters formed by the landrace and old cultivar materials (ie 2, 3, 4 and 5) were then 
Table III. Best models discriminating between "selected" and "non-selected" durum wheat entries in each season according to adjusted $R^{2}$ and probability of misclassification, and $F$-test for significance of the partial regression coefficient of the last variable entering the model.

\begin{tabular}{|c|c|c|c|c|c|c|}
\hline \multirow[t]{2}{*}{ Model } & \multicolumn{3}{|c|}{$1987-1988$} & \multicolumn{3}{|c|}{$1988-1989$} \\
\hline & $\operatorname{Adj} \mathrm{R}^{2}$ & P miscl (\%) & F obs & Adj $\mathrm{R}^{2}$ & $\mathrm{P} \operatorname{miscl}(\%)$ & Fobs \\
\hline$D H E$ & 0.264 & 25.0 & - & 0.209 & 28.2 & - \\
\hline$D H E^{2}, S P P 1$ & 0.313 & 22.3 & $5.33^{*}$ & 0.335 & 21.3 & $9.46^{\star \star}$ \\
\hline$Y L D$ & 0.332 & 21.4 & - & 0.312 & 21.5 & - \\
\hline$Y L D, G F P^{1,2}$ & 0.356 & 20.2 & 3.26 NS & 0.322 & 21.0 & 1.96 NS \\
\hline$Y L D, D H E E^{1} 2$ & 0.345 & 20.7 & $2.27 \mathrm{NS}$ & 0.308 & 21.8 & $0.51 \mathrm{NS}$ \\
\hline$Y L D, S S P 1,2$ & 0.325 & 21.8 & $0.38 \mathrm{NS}$ & 0.340 & 20.3 & $3.23 \mathrm{NS}$ \\
\hline$Y L D, D H E^{2}, S S P^{\prime}$ & 0.346 & 20.6 & 1.02 NS & 0.346 & 20.2 & $1.20 \mathrm{NS}$ \\
\hline
\end{tabular}

NS, * and ${ }^{* *}$ not significant, significant at $P \leq 0.05$ and $P \leq 0.01$, respectively. ${ }^{1}$ Last variable entering the model in $1987-1988 ;{ }^{2}$ last variable entering the model in 1988-1989.

compared in both seasons among themselves and with the improved variety "Sham 1" for all traits which were considered at least in one season for the PCA, as well as for YLD and DMA (table IV). Moroccan entries (cluster 2) performed relatively better in the more favorable season, while an opposite trend was shown in particular by the accession $C$ (cluster 4 ). In general, the groups were characterized by different combinations of positive trait levels which accounted for their good and stable performance. "Sham 1" had a consistently high number of kernels per spike in both seasons and a reduced plant stature in the wet season. The entries included in the second cluster had, on average, a distinct earliness, accompanied by a rather long GFP and a short PLH in the favorable season. The materials in the third cluster presented a relatively long GFP in both seasons. The accession $C$ (cluster 4) was characterized by a remarkably high $T K W$ in both seasons, and by a long GFP in the unfavorable season which seemed mainly attributable to its capability of delaying maturity. The entries included in cluster 5 did not show any distinct positive feature even though their characteristics were mostly related to those of the materials in clusters 3 and 4.

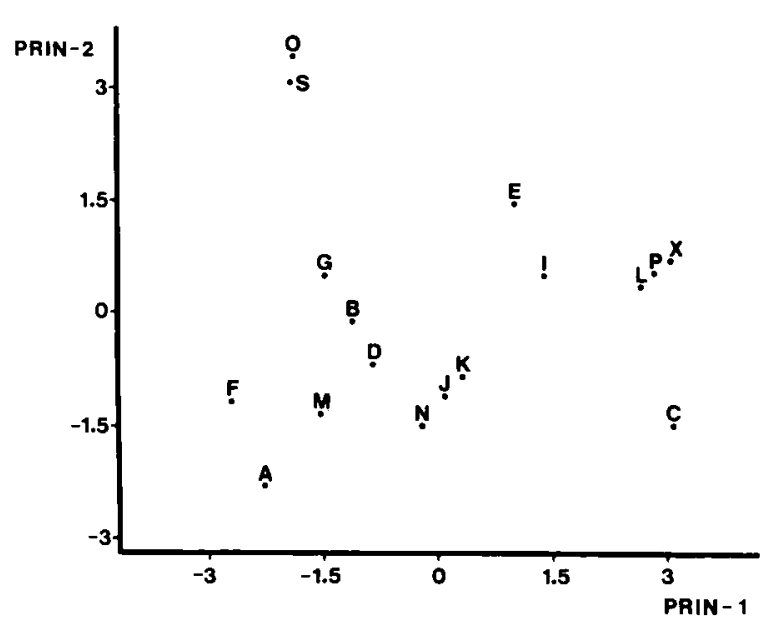

Fig 2. Scatter diagram of the 16 "selected" and of the average of the "non-selected" durum wheat entries in the space of the first 2 principal components (PRIN).

A, B, F, G, M: from Morocco; C, E, I: from Tunisia; D, J, N: from Greece; K: from Italy; P: from Jordan; L: unknown origin; S: sham 1; O: Om Rabi 9; $X$ : average of the 'non selected' entries.

\section{DISCUSSION}

In the 2 seasons, rainfall was the prevailing factor determining grain yield. In general, drought is by far the main stress factor occurring in the 
Table IV. Mean separation of 4 clusters of selected durum wheat entries and the control cultivar "Sham 1" for 8 characters in both seasons.

\begin{tabular}{|c|c|c|c|c|c|c|}
\hline Character & Season & "Sham 1" & Cluster 2 & Cluster 3 & Cluster 4 & Cluster 5 \\
\hline$Y L D$ (t/ha) & $\begin{array}{l}1987-1988 \\
1988-1989\end{array}$ & $\begin{array}{l}3.11^{\mathrm{ab}} \\
0.92^{\mathrm{a}}\end{array}$ & $\begin{array}{l}3.60^{\mathrm{a}} \\
0.88^{\mathrm{a}}\end{array}$ & $\begin{array}{l}2.98^{b} \\
0.95^{a}\end{array}$ & $\begin{array}{l}3.03^{b} \\
1.14^{a}\end{array}$ & $\begin{array}{l}2.97^{b} \\
0.94^{a}\end{array}$ \\
\hline$D H E(\mathrm{dd})$ & $\begin{array}{l}1987-1988 \\
1988-1989\end{array}$ & $\begin{array}{l}136.2^{b} \\
130.2^{a}\end{array}$ & $\begin{array}{l}131.8 \mathrm{~d} \\
127.0^{\mathrm{b}}\end{array}$ & $\begin{array}{l}134.5^{\mathrm{c}} \\
128.1^{\mathrm{b}}\end{array}$ & $\begin{array}{l}141.2^{\mathrm{a}} \\
131.0^{\mathrm{a}}\end{array}$ & $\begin{array}{l}137.7^{\mathrm{b}} \\
130.9^{\mathrm{a}}\end{array}$ \\
\hline$D M A(d d)$ & $\begin{array}{l}1987-1988 \\
1988-1989\end{array}$ & $\begin{array}{l}168.0^{b} \\
154.7^{c}\end{array}$ & $\begin{array}{l}166.1^{b} \\
154.5^{c}\end{array}$ & $\begin{array}{l}167.5^{\mathrm{b}} \\
158.1^{\mathrm{b}}\end{array}$ & $\begin{array}{l}170.0^{\mathrm{a}} \\
162.5^{\mathrm{a}}\end{array}$ & $\begin{array}{l}167.7^{\mathrm{b}} \\
157.1^{\mathrm{bc}}\end{array}$ \\
\hline$G F P(d d)$ & $\begin{array}{l}1987-1988 \\
1988-1989\end{array}$ & $\begin{array}{l}31.7^{\mathrm{b}} \\
24.5^{\mathrm{c}}\end{array}$ & $\begin{array}{l}34.3^{\mathrm{a}} \\
27.5^{\mathrm{bc}}\end{array}$ & $\begin{array}{l}33.0^{\mathrm{ab}} \\
30.1^{\mathrm{ab}}\end{array}$ & $\begin{array}{l}28.7^{c} \\
31.5^{a}\end{array}$ & $\begin{array}{l}29.9^{c} \\
26.1^{c}\end{array}$ \\
\hline$P L H(\mathrm{~cm})$ & $\begin{array}{l}1987-1988 \\
1988-1989\end{array}$ & $\begin{array}{l}92.5^{\mathrm{b}} \\
53.5^{\mathrm{b}}\end{array}$ & $\begin{array}{l}92.9^{b} \\
53.2^{b}\end{array}$ & $\begin{array}{r}123.6^{\mathrm{a}} \\
53.0^{\mathrm{b}}\end{array}$ & $\begin{array}{r}124.5^{\mathrm{a}} \\
60.5^{\mathrm{a}}\end{array}$ & $\begin{array}{r}127.2^{\mathrm{a}} \\
59.9^{\mathrm{a}}\end{array}$ \\
\hline$S S P(\mathrm{no})$ & $\begin{array}{l}1987-1988 \\
1988-1989\end{array}$ & $\begin{array}{l}57.8^{\mathrm{a}} \\
34.7^{\mathrm{a}}\end{array}$ & $\begin{array}{l}48.6^{b} \\
24.3^{b}\end{array}$ & $\begin{array}{l}42.9^{\mathrm{b}} \\
27.1^{\mathrm{b}}\end{array}$ & $\begin{array}{l}43.9^{b} \\
216.7^{b}\end{array}$ & $\begin{array}{l}43.6^{\mathrm{b}} \\
25.6^{\mathrm{b}}\end{array}$ \\
\hline LES (score) & $\begin{array}{l}1987-1988 \\
1988-1989\end{array}$ & $\begin{array}{l}3.00^{\mathrm{a}} \\
2.50^{\mathrm{a}}\end{array}$ & $\begin{array}{l}2.20^{\mathrm{b}} \\
2.60^{\mathrm{a}}\end{array}$ & $\begin{array}{l}1.75^{\mathrm{b}} \\
2.69^{\mathrm{a}}\end{array}$ & $\begin{array}{l}2.00^{\mathrm{b}} \\
2.50^{\mathrm{a}}\end{array}$ & $\begin{array}{l}3.00^{\mathrm{a}} \\
2.90^{\mathrm{a}}\end{array}$ \\
\hline$T K W(\mathrm{~g})$ & $\begin{array}{l}1987-1988 \\
1988-1989\end{array}$ & $\begin{array}{l}40.1^{c} \\
24.7^{c}\end{array}$ & $\begin{array}{l}44.8^{\mathrm{bc}} \\
30.1^{\mathrm{b}}\end{array}$ & $\begin{array}{l}43.3^{b c} \\
29.0^{b}\end{array}$ & $\begin{array}{l}50.0^{\mathrm{a}} \\
38.1^{\mathrm{a}}\end{array}$ & $\begin{array}{l}45.7^{a b} \\
30.2^{b}\end{array}$ \\
\hline
\end{tabular}

Means followed by the same letter for each character in each season are not different at $P \leq 0.05$, according to the Duncan's multiple range test.

area (ICARDA, 1991). No damage due to low temperatures was observed in either experiment season, though late frosts may influence the yield in certain seasons and frost tolerance should be taken into account while selecting for this Mediterranean region (Acevedo, 1987).

In the materials used in this study, we found that the correlation coefficient with grain yield for certain characters was influenced by the environmental conditions. In particular, the favorable precipitation level in 1987-1988 determined a yield advantage for the entries with a longer period of grain-filling and a reduced risk of lodging. Peduncle length, which has been indicated as an important selection criterion for drought tolerance (Nachit and Jarrah, 1986), was affected by its rather high correlation with $P L H(r=0.54, P \leq 0.01)$ in the favorable season and resulted positively correlated with yield only in the unfavorable one. A similar trend of variation for the correlation coefficient of both plant height and peduncle length with grain yield in function of the water received by the crop had already been reported (Nachit and Ketata, 1987; Nachit, 1988; Acevedo and Naji, 1991).

Earliness, in particular in terms of heading, and, to a lesser extent, spike fertility were the traits always highly correlated to yield as well as the main characters discriminating the materials capable of a high and stable grain yield across seasons. In the favorable season, DHE was the factor mostly determining a long GFP $(r=-0.83$, $P \leq 0.001$ ). Conversely, under drought stress an early flowering was the main feature associated with an escape strategy of the crop. Its importance in the region had already been emphasized (Ceccarelli et al, 1987; Nachit and Ketata, 1991). Kernel number generally has a conspicuous effect on the crop sink capacity in both favorable and unfavorable moisture conditions (Richards, 1987). Under drought, this trait is an indicator of stress tolerance as a part of a complex mechanism related to the plant osmoregulation ability (Morgan, 1989), even though its importance over number of fertile tillers as the main 
yield component related to yield is controversial (Gebeyehou et al, 1982; Blum et al, 1989). Under favorable conditions, Grignac (1974) indicated kernel number as the component of yield most narrowly linked with yield. The contribution of $D H E$ and $S S P$ to complement grain yield information in discriminating the best performing materials proved rather limited. Yield was the main discriminating factor but the magnitude of the genotype $x$ season interaction made difficult the assessment of genotype performance across seasons based on yield data of only 1 season, the probability of misclassification always being $>20 \%$. However, all the entries belonging to the "selected" group possessed a certain level of earliness and spike fertility whose threshold, in the conditions given, could roughly correspond to the lower range value reported in table II for this group of materials. The combination of DHE and SSP could provide a valuable selection criterion especially for the drier conditions and when grain yield could not be meaningfully assessed due to lack of seed or any other practical constraint. Indeed, a visual selection criterion mainly based on the presence of a certain earliness and high spike fertility was effective both in detecting the best materials and in predicting yield performance in the evaluation of a large durum wheat collection (Annicchiarico and Pecetti, 1990).

The comparative study among the "selected" entries evidenced that genotypes presenting different architectures of favorable traits can achieve a similar yield performance and stability. In this group, the variability for earliness and kernel number/spike contributed to the constitution of different plant types, such as the Moroccan entries and "Sham 1", but was not related to substantial differences in grain yield. Other "architectures" emerged by the combination of characters, such as $P L H, G F P$ and $T K W$ in the unfavorable season, which had not proved important in separating the best materials from the others but were related to grain yield within the "selected" group of genotypes, compensating for the lack of earliness and high spike fertility. An example of the latter plant type was the Tunisian landrace " 17870 " (C). Its good performance in the less favorable season could be attributed to its long vegetative period and the possible extent of assimilate retranslocation from the tall stem to the grain (Austin, 1989), the result being an outstandingly high kernel weight. Similar plant features were found by Blum et al (1989) in landraces collected in the Negev Desert and by Boggini et al (1990) particularly in the landrace "Tripolino" introduced into Sicily from Libya many decades ago.

The variability of plant structures related to a desirable yield response reported in this study is in agreement with the recent findings of Ceccarelli et al (1991) on barley genotypes evaluated in the same Mediterranean region. Our results indicate, on the whole, the limited interest in an integrated breeding approach based on the given agronomic traits to durum wheat germplasm selection. They also suggest the difficulty of combining mechanisms of adaptability, which are often alternative to each other, into a unique "ideotype". However, a careful selection of parents in breeding programs based on the knowledge of their trait structure could allow the combination of desirable and compatible characters into new, diversified plant types. In this study, the 2 genotypes bred for the region appeared very similar to and quite different from most of the other best performing materials in terms of plant architecture (fig 2). Though referring to a rather limited number of entries, our findings highlight the existence of plant types which have not been exploited, and perhaps not even explored, by the breeding for the region.

\section{ACKNOWLEDGMENTS}

We wish to thank Dr S Ceccarelli (ICARDA) for his useful comments and suggestions on the manuscript. The present research was undertaken as a part of the special project "Evaluation and documentation of durum wheat germplasm" supported by the Italian Government.

\section{REFERENCES}

Acevedo $E$ (1987) Assessing crop and plant attributes for cereal improvement in water-limited Mediterranean environments. In: Drought Tolerance in Winter Cereals (Srivastava JP, Porceddu E, Acevedo E, Varma S, eds) John Wiley and Sons, Chichester, 303-320

Acevedo E, Naji I (1991) Genotype characterization in durum wheat. In: Cereal Improvement Program. Annual Report for 1990. ICARDA, Aleppo, 105-115

Annicchiarico P, Pecetti L (1990) Visual evaluation of drought tolerance in durum wheat germplasm under field conditions: efficacy and comparison of scores of different complexity. Cereal Res Commun 18, 67-74

Austin RB (1989) Maximising crop production in water-limited environments. In: Drought Resistance in 
Cereals (Baker FWG, ed) CAB Int, Wallingford, 13-26

Blum A (1988) Plant Breeding for Stress Environments. CRC Press Inc, Boca Raton, FL

Blum A, Golan G, Mayer J, Sinmena B, Shpiler L, Burra $J$ (1989) The drought response of landraces of wheat from the northern Negev Desert in Israel. Euphytica 43, 87-96

Boggini G, Palumbo M, Calcagno F (1990) Characterization and utilization of Sicilian landraces of durum wheat in breeding programmes. In: Wheat Genetic Resources: Meeting Diverse Needs (Srivastava JP, Damania $A B$, eds) John Wiley and Sons, Chichester, 223-234

Ceccarelli S, Nachit MM, Ortiz Ferrara G, Mekni MS, Tahir M, van Leur J, Srivastava JP (1987) Breeding strategies for improving cereal yield and stability under drought. In: Drought Tolerance in Winter Cereals (Srivastava JP, Porceddu E, Acevedo E, Varma S, eds) John Wiley and Sons, Chichester, 101114

Ceccarelli S, Acevedo E, Grando S (1991) Breeding for yield stability in unpredictable environments: single traits, interaction between traits, and architecture of genotypes. Euphytica 56, 169-185

Clarke JM (1987) Use of physiological and morphological traits in breeding programmes to improve drought resistance in cereals. In: Drought Tolerance in Winter Cereals (Srivastava JP, Porceddu $E$, Acevedo $E$, Varma S, eds) John Wiley and Sons, Chichester, 171-190

Dagnelie P (1975a) Théorie et Méthodes Statistiques. Presses Agronomiques, Gembloux, vol 2, 2nd edn

Dagnelie P (1975b) Analyse Statistique à Plusieurs Variables. Presses Agronomiques, Gembloux

Damania AB, Somaroo BH (1988) Preliminary screening of Greek durum wheat varieties using PAGE. Rachis 7, 54-56

Duncan DB (1955) Multiple range and multiple $F$ tests. Biometrics 11, 1-42

Gebeyehou G, Knott DR, Baker RJ (1982) Relationships among durations of vegetative and grain filling phases, yield components, and grain yield in durum wheat cultivars. Crop Sci 22, 287-290

Grignac P (1974) Relations between yield, components of yields of durum wheat and certain morphological characters. In: Proc Symp Genet Breeding Durum Wheat (Scarascia Mugnozza GT, ed) Univ Bari, Bari, 275-284
ICARDA (International Center for Agricultural Research in the Dry Areas) (1989) Medium-Term Plan 1990-1994. ICARDA, Aleppo

ICARDA (International Center for Agricultural Research in the Dry Areas) (1991) Annual Report 1990. ICARDA, Aleppo

Lachenbruch PA (1968) On expected probabilities of misclassification in discriminant analysis, necessary sample size, and a relation with the multiple correlation coefficient. Biometrics 24, 823-834

Marshall DR (1987) Australian plant breeding strategies for rainfed areas. In: Drought Tolerance in Winter Cereals (Srivastava JP, Porceddu E, Acevedo E, Varma S, eds) John Wiley and Sons, Chichester, 89-100

Morgan JM (1989) Physiological traits for drought tolerance. In: Drought Resistance in Cereals (Baker FWG, ed) CAB Int, Wallingford, 53-64

Nachit MM (1988) Durum wheat breeding. In: Cereal Improvement Program. Annual Report for 1987. ICARDA, Aleppo, 40-57

Nachit MM, Jarrah M (1986) Association of some morphological characters to grain yield in durum wheat under Mediterranean dryland conditions. Rachis 5, 33-34

Nachit MM, Ketata H (1987) Durum wheat breeding. In: Cereal Improvement Program. Annual Report for 1986. ICARDA, Aleppo, 78-101

Nachit MM, Ketata H (1991) Selection of morphophysiological traits for multiple abiotic stresses resistance in durum wheat (Triticum turgidum $\mathrm{L}$ var durum). In: Physiology-Breeding of Winter Cereals for Stressed Mediterranean Environments (Acevedo $E$, Conesa AP, Monneveux P, Srivastava JP, eds) INRA, Paris, 391-400

Pecetti L, Annicchiarico P (1991) Yield potential under moderately favorable conditions, drought tolerance, resistance to yellow rust and common bunt in a world collection of durum wheat. J Genet Breed 45, 207-214

Richards RA (1982) Breeding and selecting for drought resistance in wheat. In: Drought Resistance in Crops with Emphasis on Rice. IRRI, Manila, 303-316

Richards RA (1987) Physiology and the breeding of winter-grown cereals for dry areas. In: Drought Tolerance in Winter Cereals (Srivastava JP, Porceddu E, Acevedo E, Varma S, eds) John Wiley and Sons, Chichester, 133-150

Sokal RR, Michener CD (1958) A statistical method for evaluating systematic relationships. Univ Kansas Sci Bull 38, 1409-1438 